\title{
Is There an Association Between COVID-19 Mortality and Human Development Index? The Case Study of Nigeria and Selected Low/middle Income Countries.
}

\section{Sanyaolu Alani AMEYE}

Obafemi Awolowo University Faculty of Clinical Sciences

Temitope Olumuyiwa 0jo ( $\sim$ linktopeojo@yahoo.com )

Obafemi Awolowo University https://orcid.org/0000-0003-1899-5213

Tajudin Adesegun ADETUNJI

Obafemi Awolowo University Teaching Hospital Complex

Michael Olusesan AWOLEYE

African institute for Science Policy and Innovation, OAU, Ile-Ife

\section{Research Article}

Keywords: COVID-19, Nigeria, Case Fatality Rate, Metrics, Human Development Index

Posted Date: March 2nd, 2022

DOI: https://doi.org/10.21203/rs.3.rs-1362642/v1

License: (c) (i) This work is licensed under a Creative Commons Attribution 4.0 International License.

Read Full License 


\section{Abstract}

Objectives. We assessed Case Fatality Rate (CFR) of COVID-19 as an indicator to situate the performance of Nigeria relative to other selected countries. From the available open-source datasets, we derived the case fatality rates of the different countries of interest for comparison. The CFRs were calculated as the rate of deaths compared with total cases. The values were compared with the Nigeria's COVID-19 CFR. Other relevant statistical comparisons were also conducted.

Results: The worst performing countries with regards to CFR in descending order were Yemen (19.5\%), Peru (9.0\%) Mexico (7.6\%), Sudan (7.4\%) and Ecuador (6.3\%) while the best performing nations were Bhutan $(0.11 \%)$, Burundi $(0.19 \%)$, Iceland $(0.20 \%)$, Laos $(0.21 \%)$ and Qatar $(0.25 \%)$. The CFR of Nigeria was $1.39 \%$ which falls below the 50 th percentile. Other comparison done showed significant difference in the CFR values between countries similar to Nigeria and countries that are dissimilar when HDI is used. (Mann-Whitney U test 126.0, $p=0.01$ ). The trend of the CFR in Nigeria showed a steady decline and flattening of the CFR curve which does not seem to be affected by the spikes in the daily declared cases.

\section{Introduction}

Since the declaration of the novel coronavirus disease (COVID-19) as a global pandemic on March 11, 2020,[1] it became a clear and present danger to developing countries like Nigeria. The virus eventually berthed in the country on the 27th of February, 2020, when it was detected in an Italian man who flew from Milan, Italy to Lagos, Nigeria.[2] Since then, the number of COVID-19 cases in Nigeria has increased tremendously to over 252,187 cases with the country experiencing documented four waves of the epidemic.[3]

At the onset, many public safety and non-pharmacologic measures were instituted to limit the spread of the virus. These measures included the closure of international borders, lockdown order in most states of the country, stay-at-home order for all citizens, restriction of public gatherings as well as the ban on interstate travel.[4] These aforementioned measures have since been relaxed. However, the nonpharmacological preventive measures which are still in force include the use of facemasks, frequent hand washing with soap and running water, sanitizing with alcohol-based hand rub, and physical/social distancing.[5]

SARS CoV2, the implicated virus in COVID-19, is highly infectious with a median basic reproduction rate $\left(R_{0}\right)$ of up to 5.7.[6] This makes the community transmission of COVID-19 rapid especially in settings where control measures are poorly implemented. All states in Nigeria have reported a varying number of cases and deaths.[3] with huge economic consequences as the country experienced the largest economic contraction in a decade.[7]

After over a year of the disease in the country, it is pertinent to examine the disease pattern, country performance and trends in the world's most populous black nation[8] considering the postulations that the disease has been noted to behave differently across ethnicities with the black race being worse-hit 
than the other races.[9-11] It is also important to examine country-level data relative to other affected nations. This is pertinent considering the fragile health system which is expected to be further stretched with the onset of COVID-19. Nigeria's healthcare system is plagued with poor infrastructure[12] and personnel flight[13] which has now been made worse by the pandemic. In addition, there has been poor compliance with the recommended non-pharmacologic preventive measures among the Nigerian population.[4, 14]

However, for a novel disease such as this, the information on factors affecting performance change and there is need to have a metric that can be used to access the performance. Such widely used comprehensive metric is the excess mortality, and the derivative P-score which provide information on the number of deaths from all causes during a crisis above and beyond what we would have expected to see under 'normal' conditions. [15] However, not all countries have the infrastructure and capacity to register and report all deaths. The United Nation (UN) estimates that, in "normal" times, only two-thirds of countries register at least $90 \%$ of all deaths that occur, and some countries register less than $50 \%$ and as low as under $10 \%$ deaths.[16] During the pandemic we expect this reporting to be lower. In settings where the facility report mostly all mortality exist, there are delays in death reporting.[17] In Low/Middle Income Countries (LMIC) like Nigeria, undercounting of mortality is a an issue and thus the country has no information necessary to derive the excess mortality and P-Score. The use of a the mortality rate cannot be of much value in comparing the country with others because it may not represent the true picture considering the fact that this metric is affected by the population size and the significant varied rate of testing among countries.[18]

We therefore present the simple Case Fatality Rate (CFR), which is a measurement that represents the proportion of deaths within a defined population of interest, i.e. the percentage of cases that result in death. $[19,20]$ We believe this metric is a work-around that can be used to track the performance in a setting like ours.

This study compared the performance of the country against different groups of nations using the case fatality rate (CFR). This may provide useful information to situate the burden of COVID-19 in Nigeria.

\section{Methods}

This is a secondary data analysis that compared disease severity between Nigeria and some other countries. The dataset was obtained from the "Our World In Data" (OWID) COVID-19 database[21] and the Human Development Index (HDI) database.[22] For the COVID-19 dataset, the cut-off date was the 26th of November, 2021. The required data was acquired, parsed, cleansed, and aggregated using the Python Data Science Environment[23] with essential packages such as Pandas® Library.[24]

The point case fatality rates (\%) were generated from the OWID dataset as a derivative of the total death and total cases. These case fatality estimates were derived from the currently available data as of 26th November 2021. Countries with total cases less than 1000 were however filtered out from this analysis. 
From the modified OWID dataset, the trend of new cases and case fatality rates were also calculated during the period for the country.

\section{Performance of Nigeria in Relation with Similar and Dis-similar Countries on HDI}

The case fatality rate of Nigeria was examined with neighbouring countries (Niger, Chad, Cameroon, Togo, Ghana, Benin) and continental averages.

To obtain the countries that are similar and dissimilar (countries at a maximal distance) to Nigeria in HDI, Ward's minimum-variance hierarchical clustering analysis was conducted[25] using an agglomerative (bottom-up Hierarchal Clustering up) approach and Ward's linkage on the HDI dataset. The metric of interest, i.e., the CFR was then compared between these countries and other groups of countries. The results are summarized using frequencies as well as proportions and are presented as charts.

\section{Results}

As of November 26th, 2021 the worst 5 nations with regards to CFR were Yemen (19.5\%), Peru (9.0\%) Mexico (7.6\%), Sudan (7.4\%) and Ecuador (6.3\%) while the best nations with low CFR were Bhutan $(0.11 \%)$, Burundi $(0.19 \%)$, Iceland $(0.20 \%)$, Laos $(0.21 \%)$ and Qatar $(0.25 \%)$. Nigeria at this time has had 213,883 cases with 2,063 deaths giving a CFR of $1.39 \%$. Figures 1,2 and 3 shows this rate in comparison with neighbouring countries, African Countries and Continental Averages respectively.

Based on the HDI using hierarchical clustering, six countries (Angola, Sierra Leone, Central African Republic, Ivory Coast, and Chad) were found to be similar to Nigeria. Figure S1 shows the CFR of these countries including Nigeria.

Twenty-two countries (Australia, Austria, Belgium, Canada, Cuba, Denmark, Finland, France, Germany, Iceland, Israel, Japan, South Korea, Luxembourg, Malta, Netherlands, New Zealand, Norway, Sweden, Switzerland, United Kingdom, United States) were found to be at a maximum distance with regards to similarity which implies that they were quite dissimilar to Nigeria on HDI. Figure S2 shows the general comparison of CFR among countries with similar HDIs to Nigeria and countries with dissimilar HDIs. The Mann-Whitney $U$ test $(W=126.0, p=0.01)$

Figure S3 shows the daily declared new cases and the trend of the Case Fatality Rates over the period under review.

\section{Discussions}

The OWID database is a useful and rapidly evolving database that provides great insight into the data related to COVID-19 generally and as it affects Nigeria, the most populous black nation.[26] The choice of CFR as a metric for measuring the performance of this disease and perhaps the health system was justified earlier. 
Our main focus however is on how Nigeria fared in comparison to other countries and regions. Nigeria at the time of our analysis has a CFR value that falls in the midrange of the CFR values of different countries of the World. When compared with the countries six cultural/geographical neighbours, the country ranked 4th with Togo, Ghana and Benin having lower CFR. Comparing the CFR in Nigeria to continental averages showed that while Africa still has the worst continental value, the CFR in Nigeria is only higher than that of Asia and Oceania. It is pertinent to note that the SARS CoV2 virus originated from Asia(Hua and Shaw, 2020) and more insight will be obtained if we are to drill down on the trend of the CFR on this continent.

When these countries with similar HDI were compared with Nigeria, the country ranked $5^{\text {h }}$ out of 7 with Cote d'Ivoire and Central African Republic having a lower CFR. When these two groups of countries (low and high $\mathrm{HDI}$ ) were compared our finding showed that the CFR is expectedly significantly higher in countries with low HDI. This perhaps may suggest that factors such as health facility infrastructure and capacity may have a larger influence on the CFR.

Looking at the trend, it became apparent that Nigeria had spikes in daily new cases mainly in July 2020, January to February 2021 and more recently October 2021 (rather transient spike). With regards to the CFR, the trend chart gives insight into the fact there has been a steady decline in the CFR with the period of spikes not affecting the trend of this metric. The trend information gives more insight than point calculations of CFR given that there is expectedly a lag between becoming infected and outcome.

The implication of the decreasing CFR may suggest growing herd immunity to the SARS CoV2 virus in the general populace especially in the context of widespread community transmissions. However, this work and available data lack the necessary information to test this theory.

From our findings, Yemen presents a dismal performance with regards to the CFR and this has been grossly underreported in the media and academic literature. Perhaps, the sectarian war with its attendant humanitarian crises could be responsible for this.[27](Hashim et al., 2021) In this same group of the top five countries with the worst CFR, Peru was a distant second to Yemen followed by Mexico, Sudan and Ecuador. While the scenario that applies to Yemen may apply to Sudan there appears to be no obvious reason why Mexico, Peru and Ecuador feature in this group. However, it is interesting not note that they are all South American Countries and further inquiry may yield interesting findings.

Similarly, the best performing countries however also feature some countries that elicit surprises. While it is not surprising that Iceland made this list considering her very high HDI, finding countries like Burundi, Bhutan, and Laos in this group is perhaps counterintuitive. For example, Burundi, a landlocked country in East Africa, has had her fair share of conflicts with well-documented attendant humanitarian and healthrelated problems.[28] It is therefore not expected to be among countries with the lowest CFR. Similarly, countries like Bhutan (also a landlocked country) and Laos can be regarded as developing countries.[29, 30] We explored the link between being landlocked and the possibility of limiting exposure to visitors and the different variants of the SARs CoV2 virus but Bhutan enjoys robust interactions with foreigners due to 
the recreational mountaineering activities,[31] though these recreational activities may have been slowed down by the country response which included two lock-downs implemented in the country so far.[32]

\section{Conclusion}

It is important to be cognizance of the fact that the COVID-19 pandemic is still ongoing and our understanding will continue to deepen as we acquire more data. Although it appears that Nigeria has lower case fatality rates compared to other countries with similar $\mathrm{HDI}$, we make no claim to an immutable conclusion from our effort in looking at the relevant data. Future studies should focus on the factors that may be responsible for the apparently low case fatality rates in Nigeria.

\section{Limitations}

At the beginning of the pandemic, most (African) countries had limited testing capacities[21] and this may have affected the number of cases and death reported. Similarly, there may be cases of underreporting by some countries[33] and this may also affect the official case burden recorded for the affected countries. We can only hope that as more data is gathered on this pandemic and performances as highlighted here are deeply studied, more actionable knowledge will be derived.

\section{Abbreviations}

\begin{tabular}{|ll|}
\hline CFR & Case Fatality Rate \\
\hline COVID-19 & Corona Virus Disease 2019 \\
\hline HDI & Human Development Index \\
\hline LMIC & Low/Middle Income Countries \\
\hline OWID & Our World in Data \\
\hline SARS-CoV2 & Severe Acute Respiratory Syndrome- Coronavirus 2 \\
\hline UN & United Nations \\
\hline
\end{tabular}

\section{Declarations}

\section{Availability of data and material:}

The dataset used for this study is available at https://ourworldindata.org/coronavirus-source-data

\section{Conflict of Interest:}

We declare no conflict of interest

Funding details: 
This study did not receive any funding from any individual or organization

\section{Authors' contribution:}

All authors contributed to the discussion and the final version of the manuscript. SAA conceived the study, did the data analysis, and partly drafted the initial manuscript (introduction and methods). TOO and MAA provided insightful inputs in the drafting of the manuscript's results and discussion. TOO, MAA and TAA worked on the figures and interpreted the results. All authors approved the final version of the manuscript.

\section{Ethics approval:}

A public dataset was used for this study. The available data contains country level information and not individual/personal data. Informed consent: not applicable

\section{Consent for publication:}

Not applicable.

\section{Acknowledgement:}

The second author is supported by the Consortium for Advanced Research Training in Africa (CARTA) which is funded by the Carnegie Corporation of New York (Grant No-B 8606.R02), SIDA (Grant No:54100029) and the Developing Excellence in Leadership, Training and Science in Africa (DELTAS Africa) Initiative (Grant No: 107768/Z/15/Z). The views expressed in this publication are those of the authors and not necessarily those of the partners in the consortium.

\section{References}

1. Callaway E. Time to use the p-word? Coronavirus enters dangerous new phase. Nature (Lond). 2020.

2. Nigeria Centre for Disease Control. Nigeria reports first case of COVID-19. 2020. https://ncdc.gov.ng/news/227/first-case-of-corona-virus-disease-confirmed-in-nigeria. Accessed 6 Feb 2022.

3. Nigeria Centre for Disease Control. Weekly epidemiological reports: COVID-19. 2022. https://ncdc.gov.ng/diseases/sitreps/?cat=14\&name=An. Accessed 6 Feb 2022.

4. Odusanya. COVID-19: A review of the effectiveness of non-pharmacological interventions. https://www.npmj.org/article.asp?issn=11171936; year=2020; volume=27;issue=4; ;page=261; epage=267;aulast $=$ Odusanya. Accessed 6 Feb 2022.

5. Dan-Nwafor C, Ochu CL, Elimian K, Oladejo J, llori E, Umeokonkwo C, et al. Nigeria's public health response to the COVID-19 pandemic: January to May 2020. J Glob Health. 10:020399.

6. Sanche S, Lin YT, Xu C, Romero-Severson E, Hengartner N, Ke R. High Contagiousness and Rapid Spread of Severe Acute Respiratory Syndrome Coronavirus 2. Emerg Infect Dis. 2020;26:1470-7. 
7. Yomi Kazeem. Here's how COVID-19 has battered Africa's largest economy. World Economic Forum. https://www.weforum.org/agenda/2020/08/africa-largest-economy-worst-contraction-in-a-decade/. Accessed 6 Feb 2022.

8. Kalu B. COVID-19 in Nigeria: a disease of hunger. Lancet Respir Med. 2020;8:556-7.

9. Gold JAW, Rossen LM, Ahmad FB, Sutton P, Li Z, Salvatore PP, et al. Race, Ethnicity, and Age Trends in Persons Who Died from COVID-19 - United States, May-August 2020. MMWR Morb Mortal Wkly Rep. 2020;69:1517-21.

10. Pinar, Karaca-Mandi, Archelle, Georgiou, Soumya, Sen. Assessment of COVID-19 Hospitalizations by Race/Ethnicity in 12 States | Critical Care Medicine | JAMA Internal Medicine | JAMA Network. https://jamanetwork.com/journals/jamainternalmedicine/article-abstract/2769369. Accessed 6 Feb 2022.

11. Raifman MA, Raifman JR. Disparities in the Population at Risk of Severe Illness From COVID-19 by Race/Ethnicity and Income. American Journal of Preventive Medicine. 2020;59:137-9.

12. Afolabi A, llesanmi O. Building Health System Resilience in Africa During the COVID-19 Pandemic. Global Biosecurity. 2022;3.

13. Duvivier RJ, Burch VC, Boulet JR. A comparison of physician emigration from Africa to the United States of America between 2005 and 2015. Human Resources for Health. 2017;15:41.

14. Nnama-Okechukwu CU, Chukwu NE, Nkechukwu CN. COVID-19 in Nigeria: Knowledge and compliance with preventive measures. Social Work in Public Health. 2020;35:590-602.

15. Checchi F, Roberts L. HPN Network Paper 52: Interpreting and using mortality data in humanitarian emergencies: a primer for non-epidemiologists. 2005.

16. Whittaker, C, Walker, PG., Alhaffar M, Hamlet A, Djaafara BA, Ghani A, et al. Under-reporting of deaths limits our understanding of true burden of covid-19 | The BMJ. https://www.bmj.com/content/375/bmj.n2239.abstract. Accessed 6 Feb 2022.

17. Rosenbaum JE, Stillo M, Graves N, Rivera R. Timeliness of provisional United States mortality data releases during the COVID-19 pandemic: delays associated with electronic death registration system and weekly mortality. J Public Health Pol. 2021;42:536-49.

18. Roser M, Ritchie H, Ortiz-Ospina E. Coronavirus Disease (COVID-19) - Statistics and Research. :45.

19. Byard R, Payne-James J. Encyclopedia of forensic and legal medicine. Academic Press; 2015.

20. Khafaie MA, Rahim F. Cross-Country Comparison of Case Fatality Rates of COVID-19/SARS-COV-2. Osong Public Health Res Perspect. 2020;11:74-80.

21. Ritchie H, Ortiz-Ospina E, Beltekian D, Mathieu E, Hasell J, Macdonald B, et al. Coronavirus Pandemic (COVID-19). Our World in Data. Statistics and Research. 2020.

22. Roser M. Human Development Index (HDI). Our World in Data. 2014.

23. VanderPlas J. Python data science handbook: Essential tools for working with data. O'Reilly Media, Inc.; 2016. 
24. McKinney W. Python for data analysis: Data wrangling with Pandas, NumPy, and IPython. O'Reilly Media, Inc.; 2012.

25. Murtagh F, Legendre P. Ward's hierarchical clustering method: clustering criterion and agglomerative algorithm. arXiv preprint arXiv:11116285. 2011.

26. Anyanwu MU, Festus IJ, Nwobi OC, Jaja C-JI, Oguttu JW. A perspective on Nigeria's preparedness, response and challenges to mitigating the spread of COVID-19. Challenges. 2020;11:22.

27. Hashim HT, Miranda AV, Babar MS, Essar MY, Hussain H, Ahmad S, et al. Yemen's triple emergency: Food crisis amid a civil war and COVID-19 pandemic. Public Health in Practice. 2021;2:100082.

28. Bundervoet T, Verwimp P, Akresh R. Health and civil war in rural Burundi. Journal of human Resources. 2009;44:536-63.

29. Maxwell TW. Impact of education doctorates: the case of developing country, Bhutan. Studies in Continuing Education. 2019;41:226-40.

30. Dutra LX, Haworth RJ, Taboada MB. An integrated approach to tourism planning in a developing nation: a case study from Beloi (Timor-Leste). In: Stories of practice: tourism policy and planning. Ashgate; 2011.

31. Burns GW. Gross National Happiness: A gift from Bhutan to the world. In: Positive psychology as social change. Springer; 2011. p. 73-87.

32. Tamang ST, Dorji T. Challenges and response to the second major local outbreak of COVID-19 in Bhutan. Asia Pacific Journal of Public Health. 2021;33:953-5.

33. Lau H, Khosrawipour T, Kocbach P, Ichii H, Bania J, Khosrawipour V. Evaluating the massive underreporting and undertesting of COVID-19 cases in multiple global epicenters. Pulmonology. 2021;27:110-5.

\section{Figures}




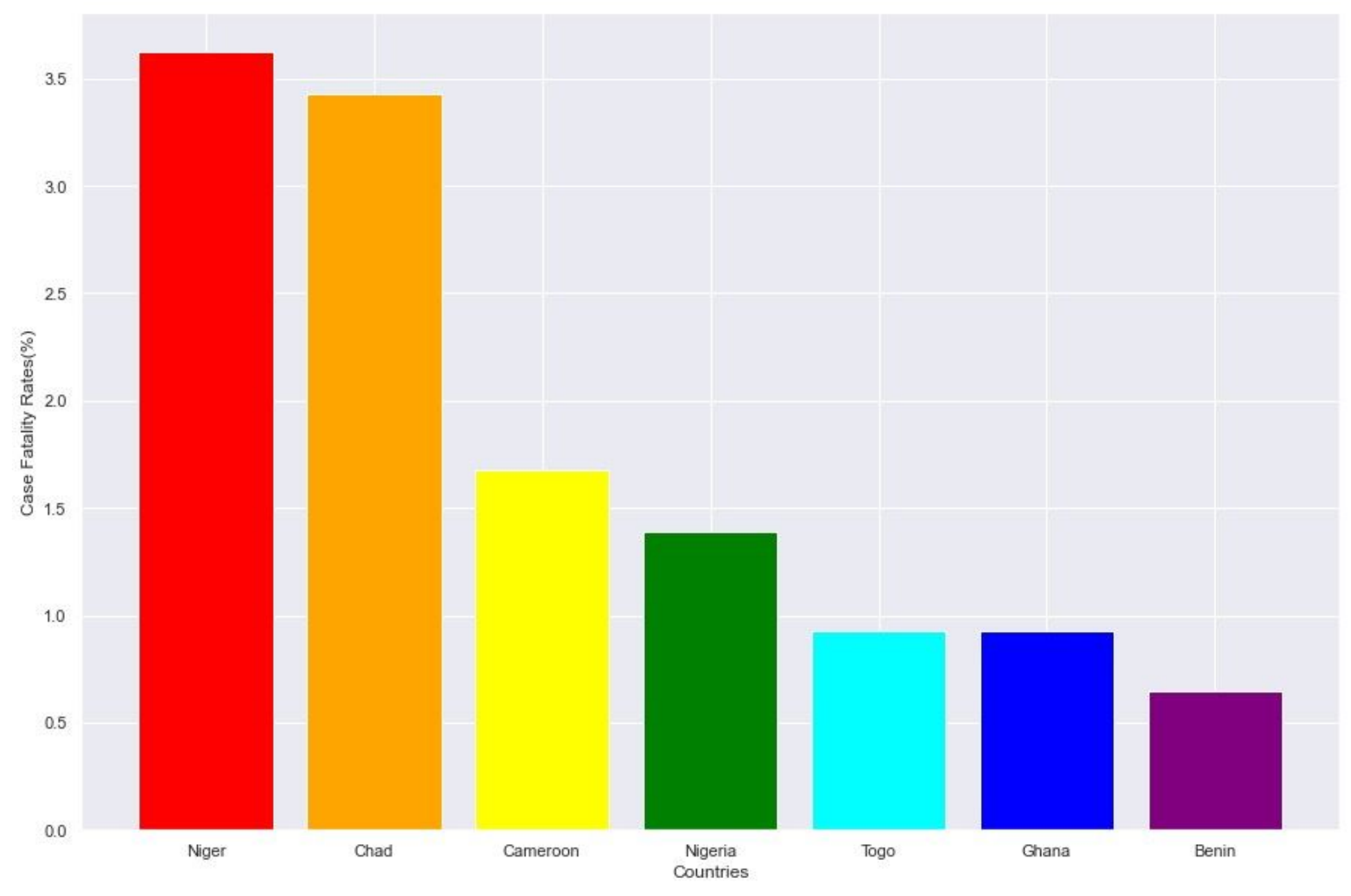

Figure 1

The Case Fatalities Rate of Nigeria and Neighbouring Countries 


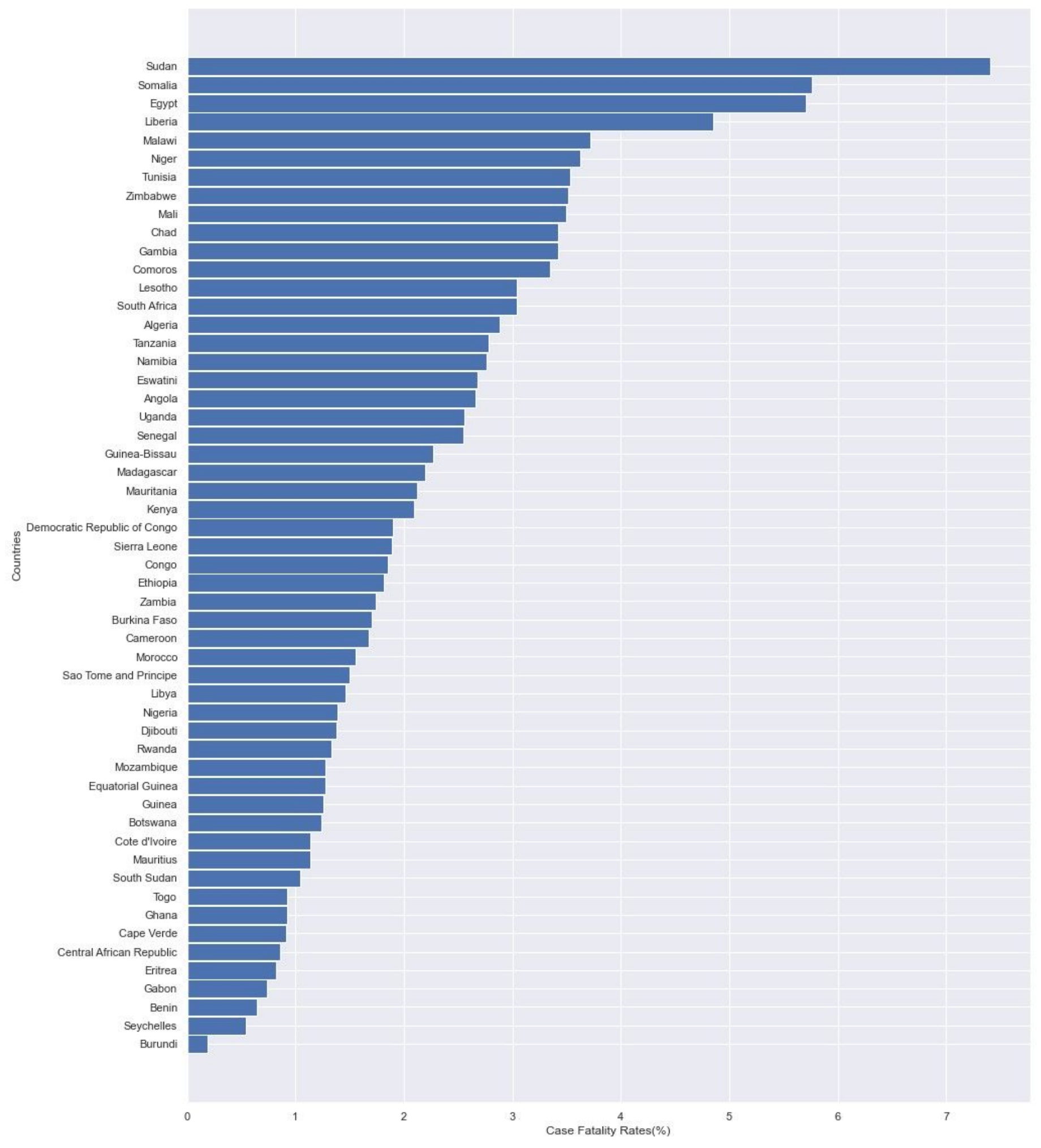

Figure 2

Case Fatality rates in African countries 


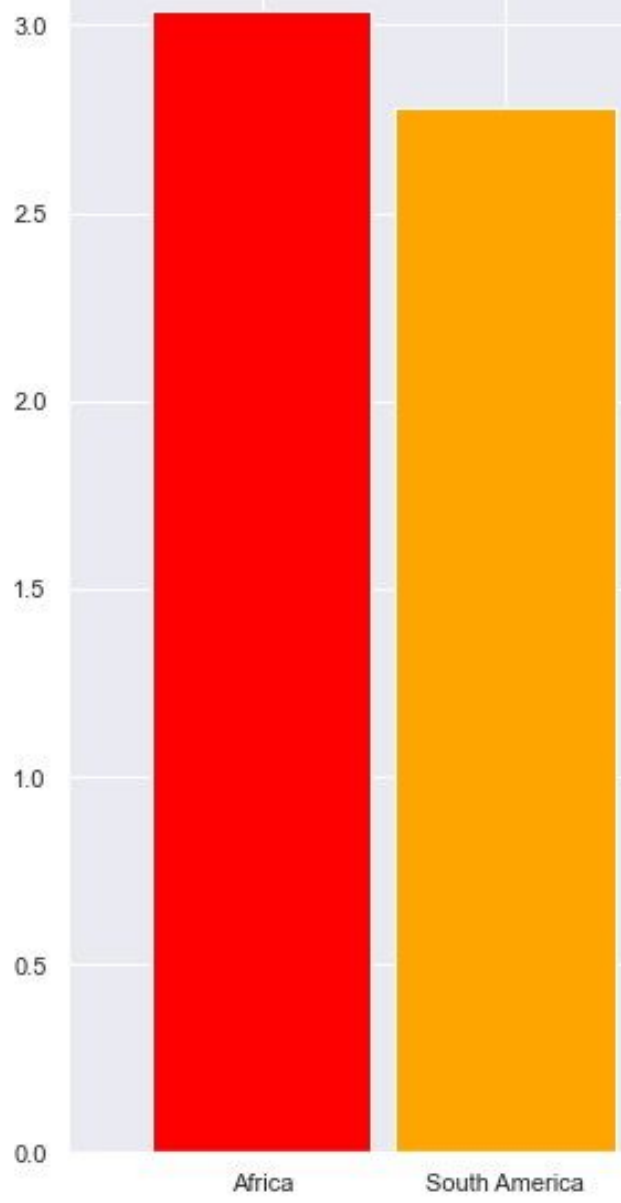

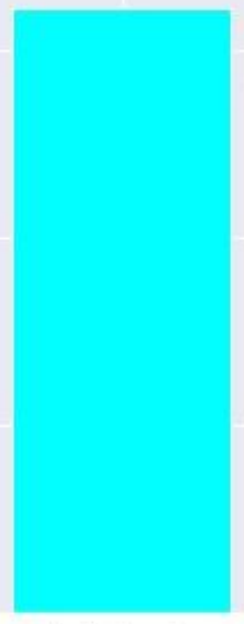

North America

Europe Continents with Nigeria Value inset for Comparison

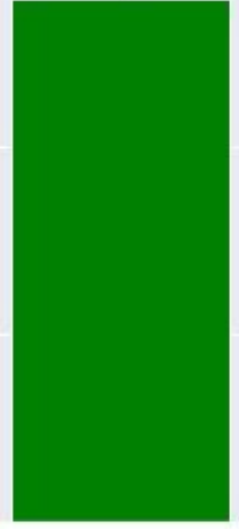

Nigeria

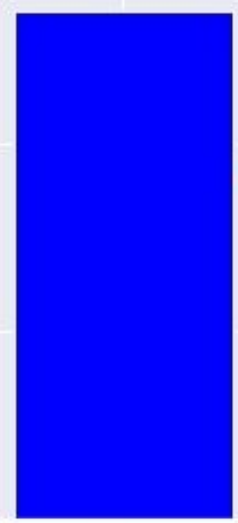

Asia

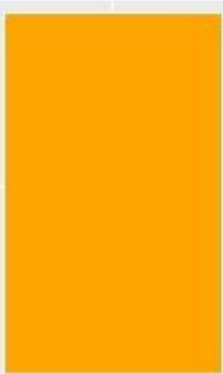

Oceania

\section{Figure 3}

The Average Case Fatality Rates across continents with the Nigerian value inset for comparison.

\section{Supplementary Files}

This is a list of supplementary files associated with this preprint. Click to download.

- Suplementaryfigures.docx 